\title{
Long-Term Results of Endoscopic Lumbar Discectomy by "Destandau's Technique”
}

\author{
Roshan Bhaisare ${ }^{1}$, Bhavna Kamble ${ }^{2}$, Kisan Patond ${ }^{3}$ \\ ${ }^{1}$ Department of Orthopaedics, Jawaharlal Nehru Medical College Sawangi (M), Wardha, MH, India \\ ${ }^{2}$ Department of Otolarynogology, Jawaharlal Nehru Medical College Sawangi (M), Wardha, MH, India \\ ${ }^{3}$ Department of Orthopaedics, Mahatma Gandhi Institute of Medical Sciences, Sevagram, Wardha, MH, India
}

\begin{abstract}
Study Design: Prospective study.
Purpose: The aim of the study was to present long-term results from a 10-year follow-up after endoscopic lumbar discectomy (ELD) by "Destandau's technique".

Overview of Literature: Endoscopic disc surgery by Destandau's technique using ENDOSPINE Karl Storz system is a relatively new technique. It was introduced in 1993. It has been gaining popularity among the spine surgeons, as it is attractive for small skin incision and allows a gentle and excellent tissue dissection with excellent visualization. Many authors have published results of their own studies; however, in all these studies the long-term follow up of the patients has not been emphasized.

Methods: A total of 21 patients selected on basis of strict inclusion criteria's underwent ELD from November 2004 to March 2005. Surgery outcome was assessed by using "Prolo's Anatomic-Functional-Economic Rating System" (1986). Patients were followed up to 10 years. In addtion, we compared the results of our study with other studies.

Results: Outcomes were excellent in 17 patients $(80.95 \%)$, good in $3(14.28 \%)$ and fair in $1(4.78 \%)$, with no patients having a poor result. In our study, 19 patients (90.47\%) were able to resume their previous works/jobs, and only 2 (9.52\%) needed to change their jobs for lighter work. No patient retired from his or her previous daily routine following the operation.

Conclusions: The initial and long-term results are very good for endoscopic lumbar discectomy by Destandau's technique. In properly selected patients it is a safe and minimally invasive technique, and we recommend ELD in properly selected patients.
\end{abstract}

Keywords: Endoscopy; Discectomy; Lumbar spine; Lumbar disc disease; Minimally invasive

\section{Introduction}

Williams [1] first described the microdiscectomy technique, which has helped as a less invasive surgical approach to the lumbar spine; however, the technique requires separation of paraspinal muscles off the lamina and the spinous process. As a result, there is associated postoperative pain and morbidity from the denervation of the paraspinal muscle complex. With the procedure, there is iatrogenic muscle injury even with a relatively small "microscopic operation" and it has been well documented [2].

Endoscopic disc surgery is a relatively new and minimally invasive technique, and endoscopic lumbar discectomy has gained increasing popularity among the spine surgeons for the treatment of herniated intervertebral disc

Received Aug 28, 2015; Revised Oct 8, 2015; Accepted Oct 8, 2015

Corresponding author: Roshan Bhaisare

Department of orthopaedics, Jawaharlal Nehru Medical College Sawangi (M), Wardha, MH, India. PIN-442004

Tel: +91-77-9823-2100, E-mail: drroshanbhaisare@gmail.com 
largely because it has the ability to overcome the limitation of muscles splitting [3]. The use of an endoscope allows the same access port and the same surgical technique to be used on the vertebral canal and disc while at the same time reducing the skin incision and minimizing the access port. The advantages of this technique are the same as those for discectomy but the immediate postoperative effects are reduced allowing a more rapid rehabilitation and return to previous activities for the patient. It is also attractive as a small skin incision with a gentle and minimal tissue dissection and excellent visualization [4].

Destandau [5] started his technique in 1993 using the ENDOSPINE Karl Storz system and reported the first series in 1999. Various authors have published the results of their own series of patients [4-7], but in those studies the follow-ups were of relatively short duration and literature on long-term results of endoscopic lumbar discectomy was lacking. The aim of this study was to present longterm results of 10 years following endoscopic lumbar discectomy.

\section{Materials and Methods}

The study was carried out on patients treated at the Department of Orthopedics, from November 2004 to April 2015 Prior approval for this work was made by the Institutional Review Board. A total of 21 patients underwent endoscopic lumbar discectomy by Destandau's technique from November 2004 to March 2005. Though we have continued to operate on patients after March 2005 we had not included them in the present study.

Indications for the surgery were: (1) radicular pain radiating in a dermatomal fashion; (2) increasing pain with nerve traction (being positive on the straight leg raise test and having the Lasegue's sign); (3) loss of sensation and/ or paresthesias in correct dermatome along with loss of motor strength and/or reflex changes in the corresponding muscles; and (4) radiculopathy consistent with a confirmatory imaging study (MRI).The following patients were excluded that had: (1) migrated, disc herniation; (2) cauda equina syndrome; (3) associated bony stenosis; (4) pedicle induced nerve root kinking; and (5) documented instability of spine.

Details of symptoms particularly of radicular pain, low back pain, and weakness were recorded. History of lifting heavy weights, distribution of pain and paresthesia, aggra- vating and relieving factors, duration and modality of any conservative treatment, and the patient's socio-economic details were also logged. Detailed spinal and neurological examinations in terms of straight leg raising test, Lasegue's sign, dermatomal sensory loss, and any motor deficit were performed. In acute disc patients, the examination was repeated after the pain subsided. In addition, plain radiographs of the patient in two projections i.e. anteroposterior and lateral view were taken. Any decreases in disc space, degeneration and bony abnormalities were searched. MRI of lumbar spine of each patient was also performed. The level of the disc, the degree of prolapse, compression of nerve roots, canal diameter changes and any other significant findings were noted in consultation with the radiologist.

\section{Surgical technique}

Patients were operated in prone position with the help of bolsters or in a knee-chest position with maximum elevation of the concerned area on a routine operating room table. General anaesthesia was used. The involved disc was localised with the help of special localization device, and the direction of approach was determined under fluoroscopic control. At the marked point, a $15 \mathrm{~mm}$ skin incision was made. The aponeurosis was incised, the paravertebral muscles were spread out, and a $12 \mathrm{~mm}$ bone chisel was inserted until it reached the posterior vertebral arch.

The ENDOSPINE (Fig. 1) operating tube with its obturator was then progressed through the incision in the direction of the posterior arc. The obturator was removed and the operating insert was put in it. Operating insert, had four portals-one for the standard 0 degree telescope (Storz), the second at 20 degrees inclination to telescope portal $(7 \mathrm{~mm}$, diameter) for the working instruments, the third for suction cannula and the fourth is the fixed nerve root retractor, which could slide up and down. The 20-degree inclination of the first two portals helped in keeping the tip of working instruments under constant vision. The outer tube also had ratchets for adjusting the depth of inner operating insert within the outer tubethis helped in selecting the magnification of the operating field.

Small part of superior lamina and the intervening ligamentum flavum was removed with a $3 \mathrm{~mm}$ Kerrison punch. To reach the compressed root and underlying protruded disc. After retracting the nerve root gently with 


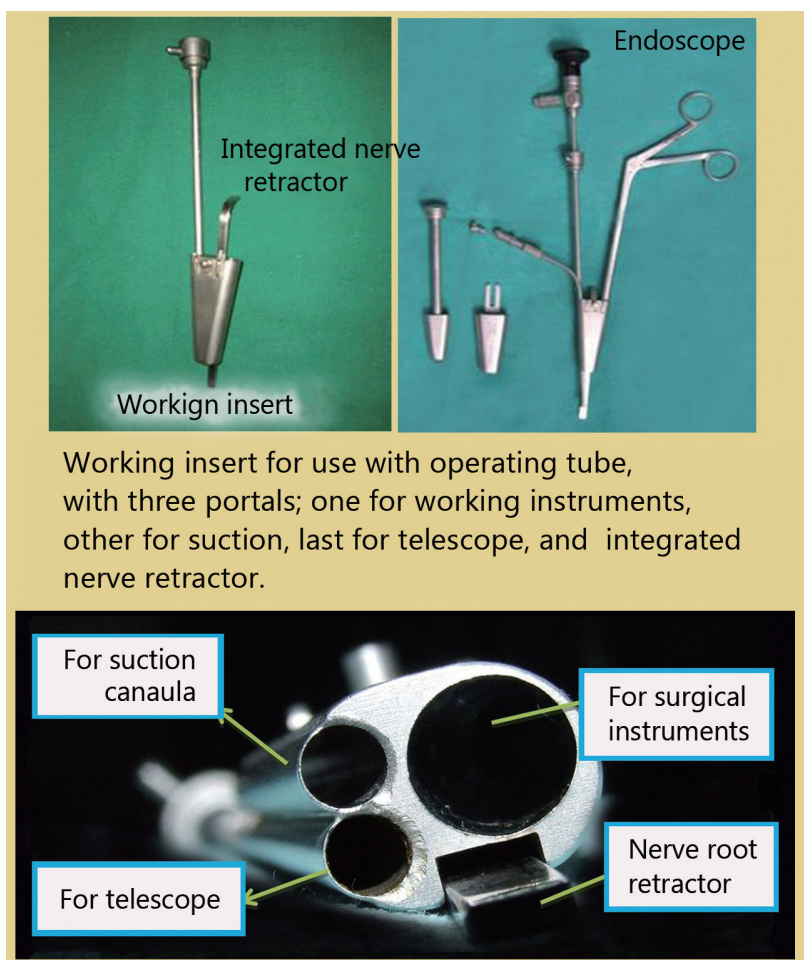

Fig. 1. ENDOSPINE Karl Storz.

a spatula and later with the in-built nerve root retractor, symptomatic disc was removed with the help of disc forceps. For a contained prolapsed disc, posterior longitudinal ligament was pierced with a small probe and discectomy was performed under vision using the disc forceps. The magnification and proper illumination decreased the chances of neural damage during the procedure. Haemostasis was achieved by bipolar coagulating forceps. After the saline wash, the wound was closed by three or four subcuticular vicryl sutures. In the end, the water proof skin dressing was applied (Figs. 2, 3).

\section{Postoperative management}

Patients were allowed to be out of bed the next day and were discharged in two to three days, if comfortable. They were allowed to do sedentary work much earlier-i.e., in two to three weeks, but were refrained from heavy manual labour for at least six weeks postoperatively.

\section{Follow-up}

The follow-up was at 6 weeks, 3 months, 1 year, $1 \frac{1}{2}$ years, 2 years and then yearly till 10 years post surgery. During

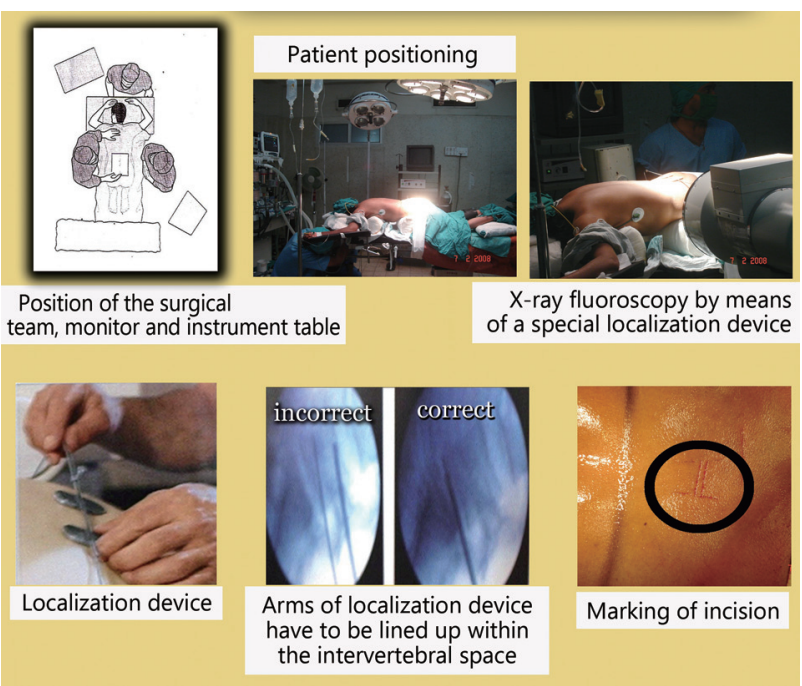

Fig. 2. Procedure: endoscopic lumbar discectomy by Destandau's technique.

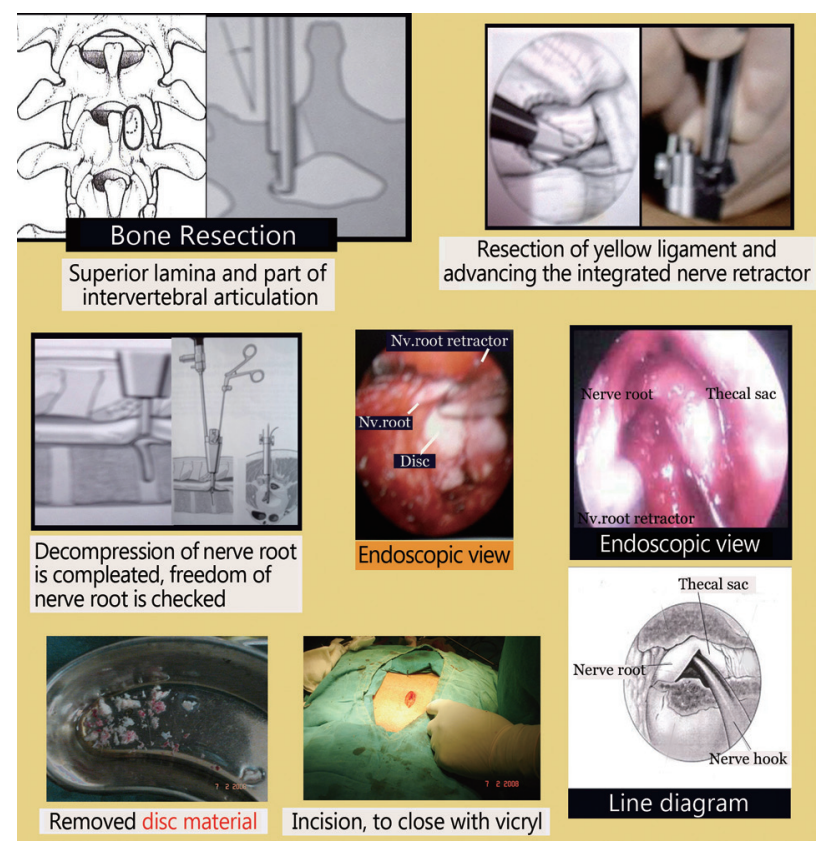

Fig. 3. Procedure (continued): endoscopic lumbar discectomy by Destandau's Technique.

each follow-up, an interview was performed regarding any new complaints, backache and radicular symptoms. Detail neurological examination was done. A quality of life assessment was also made using Prolo's AnatomicFunctional-Economic rating System [8].

\section{Observations}

Out of 21 patients, 13 were male and 8 were female. Age 
ranged from 20 to 55 years. Eight patients gave a definitive history of lifting heavy weights and in 13 patients, there was no history of associated trauma. Lifting heavy weight may be the cause of disc lesion in young patients. Radicular pain was primary complaint in 13 patients. Low back pain was primary complaint in 8 patients. Numbness and tingling were the most common words used by patients to describe sensory complaints.

Straight leg raising test was positive in 11 patients and negative in 10 patients unilaterally. Sensory deficit was observed in 9 (42.85\%) patients, motor involvement was seen in $5(23.81 \%)$ patients and weak ankle reflex was seen in $3(14.28 \%)$ patients. L5-S1 was the commonest disc involved, seen in 11 patients (52.38\%) and L4-L5 in 10 patients (47.61\%).Position of the disc was posterolateral in 13 patients $(61.90 \%)$ and posterior in 8 patients $(38.09 \%)$. On radiographs, decrease in disc space was noted in 4, straightening of of lumbosacral spine in 5 patients and degenerative changes were noted in 10 patients.

All patients were operated under general anaesthesia. Fourteen patients were operated in prone position and 7 in knee-to-chest position. Average surgical time was 11/2 hours. Average c-arm exposure for localization of entry point was 6 shoots. Discectomy was done at single level in all patients; L4-L5 in 10 patients and L5-S1 in 11 patients. Decompression was assessed by free mobility of nerve root. The average blood loss was $50 \mathrm{~mL}$ as measured from the volume in the suction chamber. No patient required a blood transfusion. One patient had a dural tear, for which the procedure was converted to open discectomy just by extending the incision and the tear was repaired with 5-0 proline suture.

\section{Postoperative complications}

One patient developed a superficial wound infection that was managed by dressing changes and oral antibiotics. One patient developed discitis and that was managed with intravenous antibiotics. Postoperative neurological detoriation developed in one parient, possibly traction neuritis, managed conservatively with neurotonics and the final result was excellent. One female patient developed perforation of the large intestine (diagnosed on the second day post-surgery). It was managed by the general surgeon with emergency laparotomy and colostomy, followed by a definitive repair at later date. The final result for the patient was good.
Preoperatively 4 (19.05\%) patients had intermittent pain and 17 (80.95\%) patients had constant pain. Postoperatively occasional pain was present in $4(19.05 \%)$ patients and 17 (80.95\%) patients were free of pain.

\section{Results}

The results were graded by Prolo's criteria based on relief from pain and resuming daily activities and work duties. The patients were followed up for 10 years at an interval of 6 weeks, 3 months, 1 year, $1 \frac{1}{1} 2$ years, 2 years and then yearly until 10 years postsurgery and the last follow-up was at the end of the study. From the study, the results were excellent in 17 patients (80.95\%), good in 3 patients (14.28\%) and fair in 1 patient (4.78\%) and none with any poor results (Figs. 4, 5).

\section{Resuming pervious activities}

In our study, 19 (90.47\%) patients were able to resume their previous professions with only 2 (9.52\%) needing to change their jobs and to switch to light work. No patient had retired from his or her previous daily routines following the operation.

\section{Re-surgery}

A patient (4.78\%) required re-surgery after 4 years (laminectomy and discectomy) following a history of lifting heavy weights, as he was a daily wage worker at a construction site. The outcome of the surgery for this patient was excellent.

\section{Discussion}

Since the first description of lumbar intervertebral disc issues leading to sciatica, various operative modalities have been developed. The classic discectomy by (Mixter and Barr [9]) underwent a series of modifications to develop into the present day discectomy procedure [3]. The classic discectomy was an extensive procedure, which required a large incision, separation and retraction of paraspinal muscles that led to an increase in postoperative morbidity such as increased pain, a delay in resuming activities and a lengthy hospital stay with significant financial burdens particularly for a developing country. Moreover for some time after the operation, the extensive surgery could lead 

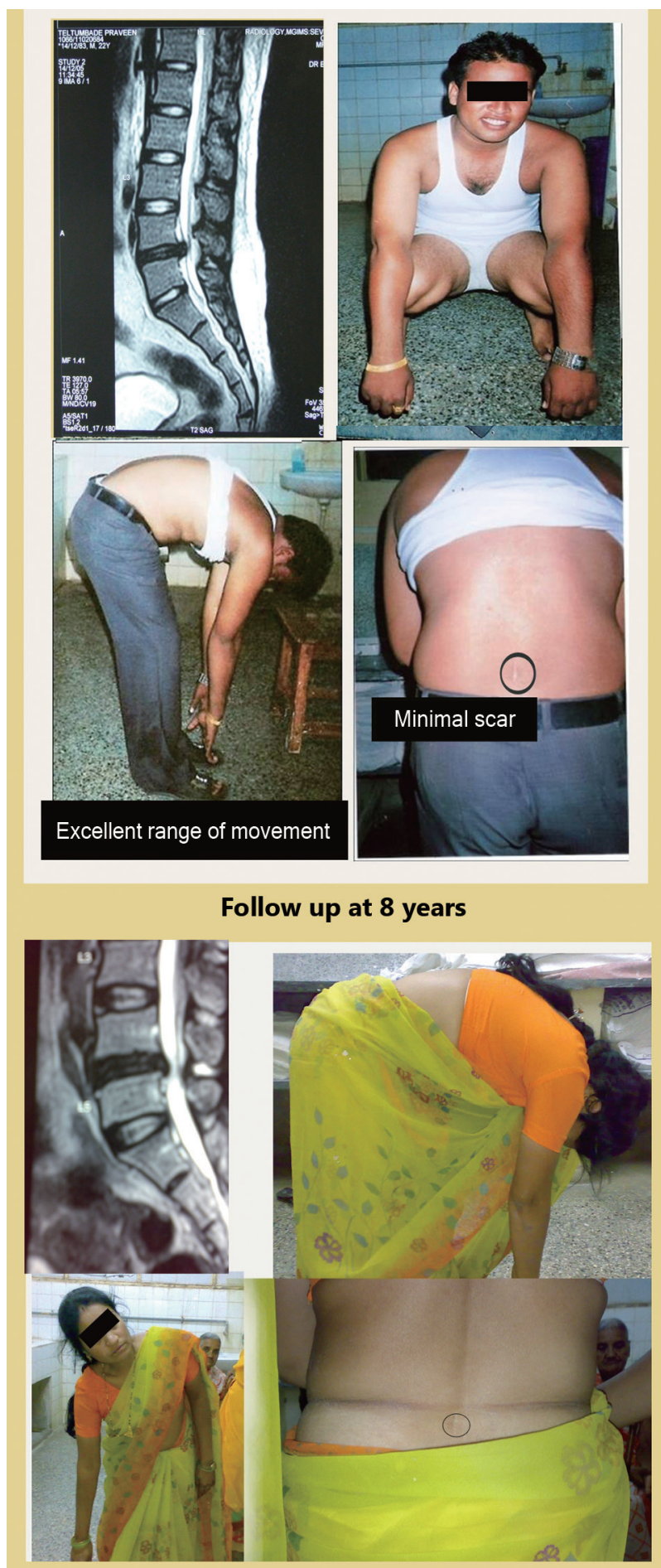

Follow up at 10 years

Fig. 4. Long-term results at 10 years.

to instability of the spine.

To overcome the disadvantages of classic discectomy, surgeons in various countries have developed a number of minimally invasive techniques such as chemonucleolysis,
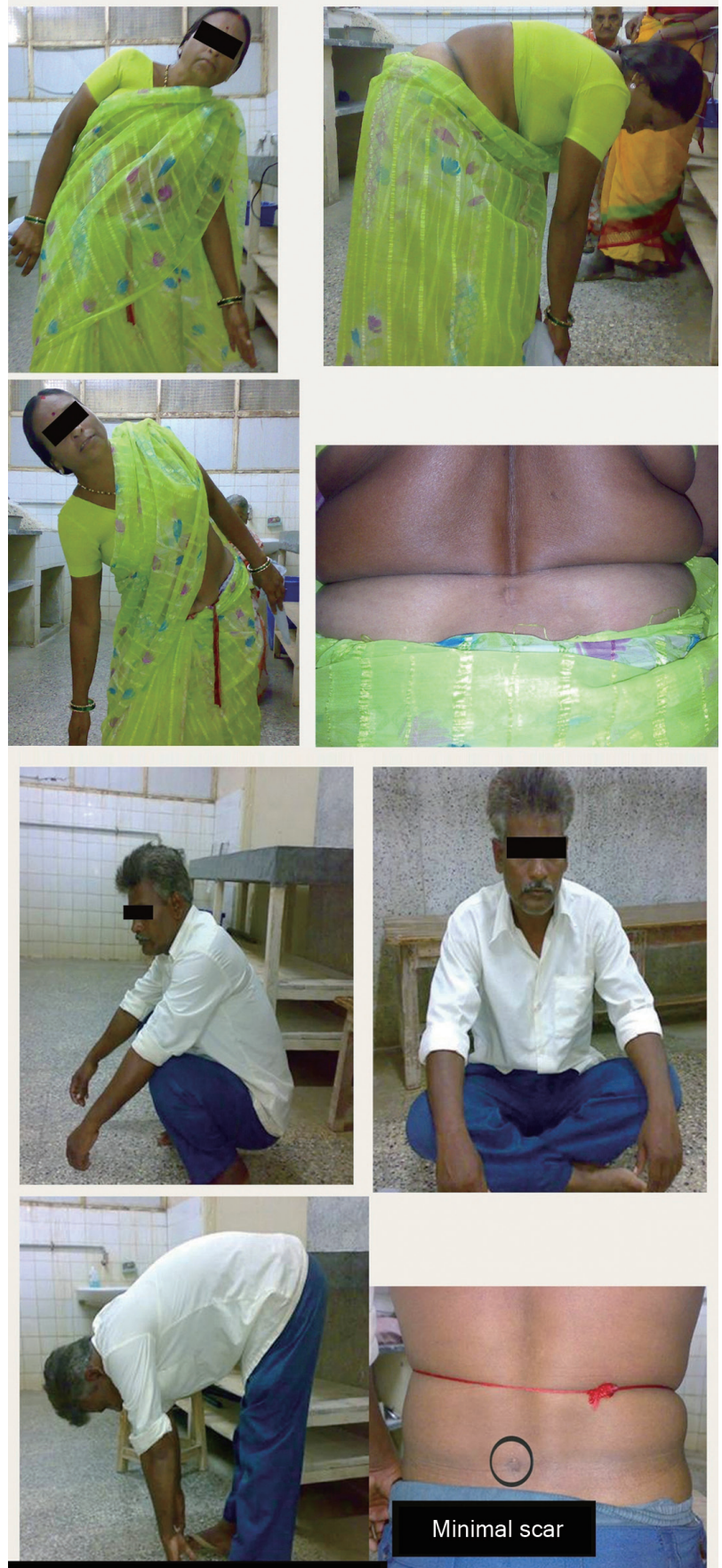

Excellent range of movement

Follow up at 10 years

Fig. 5. Long-term results at 10 years.

percutaneous discectomy (Hijikata et al. [10] and Kambin and Gellman [11]), and automated percutaneous lumbar discectomy (Onik et al. [12]). But these authors have not proposed replacing laminectomy or laminotomy and discectomy with these techniques. They only suggested that 
Table 1. Comparative study of complications occurred in all studies

\begin{tabular}{|c|c|c|c|c|c|c|c|c|}
\hline & Present study & $\%$ & Destandu, 1999 & $\%$ & Destandau, 2004 & $\%$ & Bhandari 2006 & $\%$ \\
\hline Venous bleed & 0 & 0 & 1 & 1 & 0 & 0 & 0 & 0 \\
\hline Dural tear & 1 & 4.76 & 3 & 3 & 1 & 0.69 & 2 & 7.69 \\
\hline Conversion to open & 1 & 4.76 & 0 & 0 & 2 & 1.39 & 1 & 3.84 \\
\hline Superficial infection & 1 & 4.76 & & - & & - & 1 & 3.84 \\
\hline Deep infection & 1 & 4.76 & 2 & 2 & 1 & 0.69 & 1 & 3.84 \\
\hline Temporary neurodeficit & 1 & 4.76 & & - & 3 & 2.08 & 1 & 3.84 \\
\hline Incorrect level & 0 & 4.76 & 0 & 0 & 2 & 1.39 & 0 & 0 \\
\hline Large bowel perforation & 1 & 4.76 & 0 & 0 & 0 & 0 & 0 & 0 \\
\hline Reopration & 0 & 0 & 4 & 4 & 4 & 2.78 & 0 & 0 \\
\hline
\end{tabular}

a portion of those patients scheduled to undergo an open procedure may be eligible for a less invasive approach.

In 1978, Williams [1] described microdiscectomy that helped to establish a guide as a less invasive approach to the lumbar spine. This was the mini form of conventional discectomy through a much smaller incision as compared to the previous technique. Howe and Frymoyer [13] reported a success rate of $60 \%-97 \%$ with the microdiscectomy technique. But it still required the separation of paraspinal muscles from the lamina and spinous process, which led to the denervation of the paraspinal muscle complex and causing a delay for the patient in resuming daily activity.

In 1993, Mayer and Brock [14] discussed the use of endoscopes for percutaneous discectomy and in the same year Jean Destandau from France (with ENDOSPINE Karl Storz system) performed the endoscopic discectomy by the posterior approach. As of this date, Destandau has performed more than 5,000 operations with an high rate of excellent outcomes [7].

Destandau's procedure is posterior paramedian microendoscopy which requires proper selection of patients according to list of criteria as the details of the technique are provided in the Material and Methods section. We were able to review four studies, two by Destandau [4,5] who reported his first series in 1999 and second series in 2004. Two other studies were from Bhandari [7] that reported in 2006 and Lyson et al. [6] in 2008. However in all these studies, long-term follow-up data was not adequate. For our review, we selected studies that used Prolo's criteria's for outcome analysis as ours in order to avoid any bias.

In the present study, L5-S1 disc was more commonly involved as in 11 patients (52.38\%) similar to Destandau
1999 series of 63 patients (63\%) and Bhandari 2006 series of 10 patients $(38.6 \%)$. The second most common disc was L4-L5 in 10 patients (34.6\%) in the present study, 37 patients (37\%) in Destandau 1999 study and 9 patients (42.85\%) in Bhandari 2006 study. No study has mentioned the duration of the operative procedure, which was 90 minutes in the present study.

The most frequent intraoperative complication was dural tear, as in present study it occurred in 1 patient (4.76\%). In Destandau 1999 series, dural tear occurred in 3 patients (3\%), in Destandau 2004 series in 2 patients (0.69\%), in Bhandari 2006 series in 2 patients (7.66\%). Generally it occurred in the learning phase for the procedure and the rates diminished as the surgeon became more familiar with the instrumentation and the protocol. In the present study, conversion to open surgery was needed for 1 patient (4.76\%), in Destandau 2004 study it was needed in 2 patients (1.39\%), and in Bhandari 2006 study needed in 1 patient (3.84\%). Superficial infection occurred in 1 patient $(4.76 \%)$ in the present study and in 1 patient $(3.84 \%)$ in Bhandari 2006 study.

\section{Comparative study of complications in all the studies (Table 1)}

Deep infection i.e., discitis occurred in every series; in the present study it occurred in 1 patient (4.76\%), in Destandau 1999 study in 2 patients (2\%), in Destandau 2004 study in 1 patient (0.69\%), and in Bhandari 2006 study in 1 patient $(3.84 \%)$. Temporary neuro-deficit in the present study was seen in 1 patient (4.76\%), in Destandau 2004 series in 3 patients (2.08\%) and Bhandari 2006 series in 1 patient $(3.8 \%)$. Incorrect level of operation due to er- 
Table 2. It was easier to compare results as each study graded results on basis of Prolo's criterias [8]

\begin{tabular}{|c|c|c|c|c|c|c|}
\hline & Present study & $\%$ & Destandau, 1999 & $\%$ & Destandau, 2004 & $\%$ \\
\hline Excellent & 17 & 80.95 & 78 & 85.71 & 130 & 90.27 \\
\hline Good & 3 & 14.28 & 9 & 9.89 & 1 & 0.69 \\
\hline Fair & 1 & 4.78 & 0 & 0 & 0 & 0 \\
\hline Poor & 0 & 0 & 4 & 4.39 & 13 & 9.02 \\
\hline No. of patients & 21 & - & 91 & - & 144 & - \\
\hline
\end{tabular}

ror in localization of incision occurred in no patients in the present study while it happened in 2 patients $(1.39 \%)$ in Destandau 2004 series. Large bowel perforation was reported in the present study in 1 patient $(4.76 \%)$. No patient required immediate re-operation in the present study while it was required in 4 patients (4\%) in Destandau 1999 study and 4 patients (2.78\%) in Destandau 2004 study. If both series of Destandau are compared, the complication rate was lower in second series (2004) as compared to the first series (1999), which may indicate that the complications decrease as the surgeon gains experience with the technique.

The average hospital stay in our study was 3.5 days as compared to 3.4 days in Bhandari 2004 study. The average delay in resuming previous activity/work in present study was 7 weeks as compared to 3 weeks in Destandau 2004 study and Bhandari 2006 study. For our patients, as most were from the manual labor category, and considering that we expected a poor compliance with the postoperative instructions, the request to minimize activity before returning to normal activities was made in order to avoid complications.

\section{Resuming previous activities}

In our study, 19 (90.47\%) patients were able to resume their previous works/jobs with only 2 (9.52\%) needing to change jobs because of physical demands. No patient had changed his or her previous daily habits following the operation. The results were comparable to Destandau 2004 series where out of 80 patients (having jobs preoperatively), 77 patients (96.25\%) were able to resume previous jobs, 2 patients $(2.50 \%)$ required job modification, and 1 patient $(1.25 \%)$ had to retire from work.

\section{Results}

It was easier to compare results as each study graded results on basis of Prolo's criteria (Table 2) [8].

In the present study, the results were excellent in 17 patients $(80.95 \%)$, good in 3 patients $(14.28 \%)$ and fair in 1 patient $(4.78 \%)$ and no patients with any poor results. In comparison to the Destandau 1999 series that showed excellent results in 78 patients (85.71\%), good in 9 patients $(9.89 \%)$, none with fair results, and poor in 4 patients (4.39\%). The results of Destandau 2004 series were excellent in 130 patients $(90.27 \%)$, good in 1 patient (0.69\%), poor in 13 patients $(9.02 \%)$, and none with fair result. In our study one patient was re-operated after 4 years with excellent results.

The results of the present study are comparable to the previous studies. With $95.23 \%$ of patients with excellent and good results and $4.78 \%$ with fair results, $90.47 \%$ patients resuming the previous work/activity, with decrease in hospital stay of 3.5 days and negligible postoperative morbidity, there is a strong association that the endoscopic lumbar discectomy by Destandau's technique is an effective procedure in properly selected candidates requiring lumbar disc surgery. During this study, we were in a learning phase as with more experience with the instruments and the procedure, the complication rates will decrease and results will improve; this will also allow the indications for the technique to be extended and a possible inclusion of more candidates for surgery in the near future.

We also compared the results of our study with a study comparing conservative management versus surgical management of lumbar disc herniation. A long-term study was performed by Atlas et al. [15] on the outcomes of non-surgical and surgical management of lumbar disc herniation. A total of 507 patients were managed conservatively and surgically. The results were analysed using Modified Roland back specific functional status scale. At the end of 10 years, 477 patients were surviving and from these, 400 patients completed the 10 year follow-up. Out of 400 patients, 217 were managed surgically and 183 
were managed conservatively. At the end of 10 years, 25\% of patients who were initially managed surgically needed at least one extra surgery. And 25\% of patients, who were initially managed conservatively, needed at least one lumbar spine surgery. Sixy-nine percent of patients who were managed with surgery reported improvement in their symptoms compared to $61 \%$ patients who were initially managed conservatively. Patients who were managed by surgery reported their symptoms like low back ache and radicular symptoms were much better or completely gone (56\% vs. $40 \%$ ) and were more satisfied with their current status. The authors concluded that, though this data favored surgical interventation, the work and disability status of the patients at 10 years were comparable for those treated either surgically or non-surgically.

Comparing results of the study with a study of standard lumbosacral discectomy, Lewis et al. [16] in their longterm prospective study of lumbosacral discectomy reported that the second operation rate in surgically treated patient was $25 \%$. In our study the re-surgry percentage was $4.78 \%$. This could be due to the significant selection bias in our study as the inclusion and exclusion criteria were clearly defined. In Lewis et al.s study, at the end of 5 to 10 years, $93 \%$ of patients were able to return to their previous work (versus $90.5 \%$ in our study), and $96 \%$ were pleased by surgery. Eleven percent reported that their leg pain was severe or worsen after surgery, and the re-operation rate was $18 \%$. The authors concluded that the results of lumbosacral discectomy were favourable but preoperative factors which were significantly associated with outcome at 1 year postoperatively were not associated with outcome at 5 to 10 years. In a retrospective study by Yorimitsu et al. [17], patients who were operated by standard discectomy were observed for a minimum of 10 years. They were evaluated on Japanees Orthopaedic Association Scores and it was $73.5 \% \pm 21.7 \%$. Residual back pain was found in 74.6 patients, and only $12.7 \%$ had severe backache. In addition, the long-term outcomes of standard discectomy were favourable.

We also reviewed the long-term outcomes of various posterior discectomy techniques. Gotfryd and Avanzi [18] made a systematic review of randomised clinical trials using posterior discectomy techniques to treat lumbar disc herniation by classic, microscopic, and posterior endoscopic discectomy surgical techniques. They reviewed electronic databases, made manual searches, had personal communications and found 1,360 titles for preliminary review. They selected 25 studies which met the inclusion criteria, and in consensus meeting with the authors, they discarded 15 articles. They proposed that there was no statistically significant difference between these techniques regarding improvement in pain, sensory deficits, motor strength, reflexes, and patient satisfaction. The inclusion criteria for this study was patient age between 20-60 years, a single level lumbar disc herniation, not responding to conservative treatment. Exclusion criterias were the presence of a herniated disc involving more than one anatomical level, degenerative narrowing of the spinal canal, spondylolisthesis, and re-operations. These criteria's were mostly similar to the present study.

\section{Conclusions}

Endoscopic discectomy by Destandau's technique for lumbar prolapsed intervertebral disc in properly selected patients is a safe and minimally invasive technique. $\mathrm{Pa}$ tients are mobilized early and are comfortable after surgery because of reduced pain. The hospital stay is also significantly reduced and they can go back to work early. The initial and long-term results are excellent.

\section{Conflict of Interest}

No potential conflict of interest relevant to this article was reported.

\section{Acknowledgments}

I thank all the patients who had given their consent to be a part of this study. The guidance provide by my guide Prof. K.R. Patond was unparallel, I thank him for the same. Dr Bhavna Kamble had done the data collection, helped in review of literature and manuscript writing, I sincerely acknowledge her support.

\section{References}

1. Williams RW. Microlumbar discectomy: a conservative surgical approach to the virgin herniated lumbar disc. Spine (Phila Pa 1976) 1978;3:175-82.

2. See DH, Kraft GH. Electromyography in paraspinal muscles following surgery for root compression. Arch Phys Med Rehabil 1975;56:80-3.

3. Smith MM, Foley KT. Microendoscopic discetomy 
(MED): surgical technique and initial clinical results. Proceedings of the Thirteen annual Meeting of the joint section of Disorders of the Spine and Peripheral Nerve of the American Association of Neurological Surgeons; 1997 Feb; Newport Beach, CA.

4. Destandau J. A special device for endoscopic surgery of lumbar disc herniation. Neurol Res 1999;21:39-42.

5. Destandau J. Technical features of endoscopic surgery for lumbar disc herniation: 191 patients. Neurochirurgie 2004;50:6-10.

6. Lyson T, Mariak Z, Jadeszko M, Kochanowicz J, Lewko J. Results of Destandau microendoscopic lumbar discectomy. Neurol Neurochir Pol 2008;42:10511.

7. Bhandari S. Early experiences in endoscopic lumbar discectomy by destandau technique for prolapse intervertebral disc. J Maharashtra Orthop Assoc 2006; 4:174-79.

8. Prolo DJ, Oklund SA, Butcher M. Toward uniformity in evaluating results of lumbar spine operations. A paradigm applied to posterior lumbar interbody fusions. Spine (Phila Pa 1976) 1986;11:601-6.

9. Mixter WJ, Barr JS. Rupture of the intervertebral disc with involvement of the spinal canal. N Engl J Med 1934;211:210-5.

10. Hijikata S, Nakayama T, Yamagashi M, Ichihara M. A new treatment method for lumbar disc. Toden Hosp 1975;5:39-44.

11. Kambin P, Gellman H. Percutaneous lateral discec- tomy of the lumbar spine a preliminary report. Clin Orthop Relat Res 1983;174:127-32.

12. Onik G, Helms CA, Ginsburg L, Hoaglund FT, Morris J. Percutaneous lumbar diskectomy using a new aspiration probe. AJR Am J Roentgenol 1985;144: 1137-40.

13. Howe J, Frymoyer JW. The effects of questionnaire design on the determination of end results in lumbar spinal surgery. Spine (Phila Pa 1976) 1985;10:804-5.

14. Mayer HM, Brock M. Percutaneous endoscopic discectomy: surgical technique and preliminary results compared to microsurgical discectomy. J Neurosurg 1993;78:216-25.

15. Atlas SJ, Keller RB, Wu YA, Deyo RA, Singer DE. Long-term outcomes of surgical and nonsurgical management of sciatica secondary to a lumbar disc herniation: 10 year results from the maine lumbar spine study. Spine (Phila Pa 1976) 2005;30:927-35.

16. Lewis PJ, Weir BK, Broad RW, Grace MG. Long-term prospective study of lumbosacral discectomy. J Neurosurg 1987;67:49-53.

17. Yorimitsu E, Chiba K, Toyama Y, Hirabayashi K. Long-term outcomes of standard discectomy for lumbar disc herniation: a follow-up study of more than 10 years. Spine (Phila Pa 1976) 2001;26:652-7.

18. Gotfryd A, Avanzi O. A systematic review of randomised clinical trials using posterior discectomy to treat lumbar disc herniations. Int Orthop 2009;33:117. 